book are of this complexity and are hard to interpret. Some of them are made difficult by being wrongly labelled.

But it is a good book. It brings together the recent work of both American and European zoogeographers, and provides a survey suitable for undergraduates specializing in the distribution of land animals and for graduates in need of a brief introduction to the subject and its literature.

Wilma George

\section{MINORITY VIEW OF SYSTEMATICS}

\section{Classification and Biology}

By R. A. Crowson. Pp. xiii + 303. (Heinemann (Educational): London, March 1970.) 63s.

As an eminent beetle taxonomist, R. A. Crowson is well qualified to discuss the methods and goals of systematics. His Classification and Biology covers a wide range of topics, many of which are long overdue for an exposition based upon first-hand experience.

One of Crowson's more stimulating ideas has to do with the effects of different goals and materials on the way in which biologists classify. He observes that museum taxonomists, concerned with identification, work by associating specimens and then groups into increasingly larger units. Academic systematists, on the other hand, tend to proceed in the opposite direction, starting with larger assemblages and dividing them up. Likewise palaeontologists, with fragmentary but datable materials, find it easy to deal with historical relationships, but have trouble applying the concepts of population genetics.

Crowson's own views may be analysed on the same basis. Concerned with the higher classification of a large and widely distributed group of organisms, rich in anatomical detail but poor in fossils, he naturally approaches systematics from a phylogenetic point of view. His discussions of host-parasite relationships and of biogeographical evidence are particularly useful, especially because such evidence has largely been ignored in recent polemics. By the same token we may see much merit in his stress on strictly monophyletic taxa. If we want to understand the evolution of symbiotic relationships or patterns of distribution, we need to know genealogies, not levels of organization. On the other hand, his proposals for ranking taxa according to their age seem no more workable than some of the excesses he criticizes. For some reason he ignores a paper by Hull which shows the weakness of his approach, and one by Mayr which argues for a reasonable compromise.

In his discussions of philosophy Crowson rightly points out that insufficient attention has been paid to the bearing of diversity and history on our understanding of nature. But he seems to vacillate, and to embrace inconsistencies, with respect to the objectivity of historical knowledge and of classification systems. He invokes a need for objectivity as a reason for ranking on the basis of age and for strictly monophyletic taxa. On the other hand, he fails to see this very advantage in the biological definition of a "species" which he inadequately distinguishes from the sterility test. And his attack on our codes of nomenclature misses the rationale of the procedure used in naming taxa. Scientists have every reason for having the properties of actual organisms, rather than somebody's opinion, determine the applicability of a name. If taxa correspond to populations or lineages, then membership is a matter of fact, not opinion. To extend Crowson's own metaphor, the international committees are, and should be, legislators rather than jurors.

Crowson's book is a clear and forthright, if rather cantankerous, statement of a minority point of view. He comes up with some delightful ironies, but some readers may wonder why he needs to blame so many of the world's ills on the United States. If read with an awareness of the context in which it was written, the book should be rewarding to anybody seriously interested in classification. In addition, the very thoughtful final chapter on the future of systematics contains many ideas which ought to be considered by all biologists when they plan the develop. ment of their curricula and institutions.

Michael T. Ghiselin

\section{PLACENTAL MORPHOLOGY}

\section{The Human Placenta}

By J. D. Boyd and W. J. Hamilton. Pp. $\mathrm{xv} \div 365$. (Heffer: Cambridge, April 1970.) 360s.

IT is sad that this volume has appeared two years after the death of the first author and during the retirement year of the second. Nonetheless its appearance at this time may be appropriate because it will certainly come to be regarded as a monument to two of the great placental morphologists of all time.

Not only are the very considerable advanees that the authors have made gathered together in one place, but Boyd and Hamilton's interest in the subject is further demonstrated by the fascinating historical section and the most comprehensive bibliography. In the past they have often stressed the importance of a knowledge of the earlier Continental, especially German, literature to the placentologist and they have rendered a great service not only in compiling this bibliography but also in quoting freely from the original articles.

The text itself is clear and concise and the illustrations are of very high quality, although one must regret the fact that their very frequency has often made it necessary to print illustrations well away from the point of reference in the text. The many problems in placental morphology are fully discussed with impartiality except where the authors' own work leads them to be dogmatic, as it does, for instance, about the marginal sinus.

The paucity of spelling and typographical errors is a tribute to careful proof reading, but it is surprising to find in a book by two such eminent anatomists the abbreviation "S.H." defined on page 28 as meaning "standing height" (crown-heel length) and on page 78 as "sitting height" (crown-rump length). I have great admiration for the careful avoidance of anything approaching jargon although this has sometimes led to the use of unaccustomed phrases such as "tinctorial affinities". Perhaps the anxiety of the authors to cover the whole subject has led them to discuss problems of pathology which are not in their realm of absolute expertise and about which their pronouncements are, at least, controversial.

The most serious criticism that can be levelled against this book is its price. One understands that its extremely high quality must have made production costs heavy and also that it is most unlikely to have a large sale as a standard textbook for the undergraduate. Nonetheless it is a book which will remain a classic in its field and it seems unfortunate that its very high price will make it difficult for the young worker in the realm of placentology to own his copy, which is the way in which he would best be able to read, learn and inwardly digest this splendid work.

GEOFFREY DiXoN

\section{PERSONAL NEUROLOGY}

\section{Brain Diseases}

By A. Biemond. Pp. xxi+879. (Elsevier: Amsterdam, London and New York, 1970.) $480 s$.

THE appearance of an English edition of a Continental neurological textbook by a distinguished colleague is an unusual and welcome event. Professor Biemond's Brain Diseases was first published in Dutch in 1946. Based on his extensive clinical experience, and supported by 